\title{
An approach to evaluating block and panel cave projects for sensor-based sorting applications
}

\author{
S Nadolski The University of British Columbia, Canada \\ B Klein The University of British Columbia, Canada \\ CJR Hart Mineral Deposit Research Unit, Canada
}

A Moss The University of British Columbia, Canada

D Elmo The University of British Columbia, Canada

\begin{abstract}
Advances in sensor-based sorting technologies in mineral applications have resulted in increased interest in the implementation of sorting systems at mining operations. Ore sorting holds significant potential to improve the productivity at block and panel caving operations, where the lack of selectivity and potential for dilution entry associated with the cave mining methods results in many operations mining and processing material that is below cutoff grade at certain stages of production.

A sensor-based ore-sorting study, incorporating bulk and particle sorting systems, was carried out using material from the New Afton block cave operation. Results from the study were used to develop a method for evaluating future lifts where sensor-based sorting systems are in place. A case study is presented for a conceptual cave where both bulk and particle sorting systems are implemented. The method provides a means to nominate a cave footprint and elevation that maximises project value in the case where sensor-based sorting systems are installed. Through use of production scheduling software, the proposed method can be used to determine the economic footprint, reduction in milling requirements and associated metal recovery for a cave.
\end{abstract}

Keywords: block caving, sensor-based sorting, PCBC, cave-to-mill, cave evaluation

\section{Introduction}

The non-selectivity of block and panel caving methods results in many caving operations having to mine and process material that is below cutoff grade. The industry trend of increasing caving lift size, in terms of column height and footprint area, brings about greater risk of unbudgeted dilution. In many cases, footprints include 'waste' drawpoints, which have minimal or no projected production of above cutoff grade material, that are blasted to achieve a sufficiently large hydraulic radius for cave initiation, and are drawn to maintain cave propagation. Bulk and particle sensor-based sorting systems provide a means to reliably separate ore and waste from caved material, either at the extraction level or after it has been transported to surface.

A growing number of mining operations are implementing sensor-based sorting technologies to pre-concentrate excavated material. Sensor technologies can be mounted on shovels, hoppers and conveyors, and sorted as bulk lots of material or on a particle-by-particle basis. Sensor types for mineral applications include prompt gamma neutron activation analysis (PGNAA), optical, $X$-ray transmission (XRT), $X$-ray luminescence $(X R L)$, near-infrared, $X$-ray fluorescence $(X R F)$, electromagnetic and radiometric sensors (Klein \& Bamber 2018; Kobzev 2014).

At Newcrest's Ridgeway Deeps mine, trials of a magnetic resonance (MR) sensor for rapid (20 second) bulk sensing of chalcopyrite, the main copper-bearing mineral, showed that the technology has potential for use in a bulk sorting system through integration with a diverter (Coghill et al. 2018). Teck trialled shovel-mounted XRF sensors at their Highland Valley Copper operations to measure grade information in real time and instruct operators whether loads are to be sent to ore or waste stockpiles (Teck Resources 2018). At the 
Priargunsky mine in Russia, both bulk and particle sorting systems are used for beneficiation of uranium ore. On a bulk scale, the grade of material inside rail cars or dump trucks is measured using XRF sensors; material that is above cutoff grade is fed to particle sorters for further beneficiation while low-grade material is directed to a heap leaching site (Kobzev 2014).

Cave evaluation involves the use of planning and scheduling software to determine the associated value of a caving lift for an orebody. Geological block models, which include revenue factors such as mining cost and mill recovery, can be input by users along with the planned extents of the extraction level to determine the best height of draw (BHOD) for each drawpoint and the associated project value (Diering et al. 2010). Development of a block parameter which represents sorting performance provides an opportunity to include sensor-based sorting in the footprint specification and production scheduling solutions and determine the associated project value.

This paper presents a method for including sensor-based sorting parameters in the outputs of the PCBC ${ }^{\mathrm{TM}}$ cave planning and production scheduling module within the GEMS GEOVIA, version 6.8.1 package (Dassault Systèmes 2018). Results from a sorting study carried out at the New Afton block cave mine were used to demonstrate the method for a conceptual cave in a copper-porphyry deposit.

\section{Methodology}

A summary of the proposed method for determining the economic cave footprint and associated value for a grade block model is shown in Figure 1.

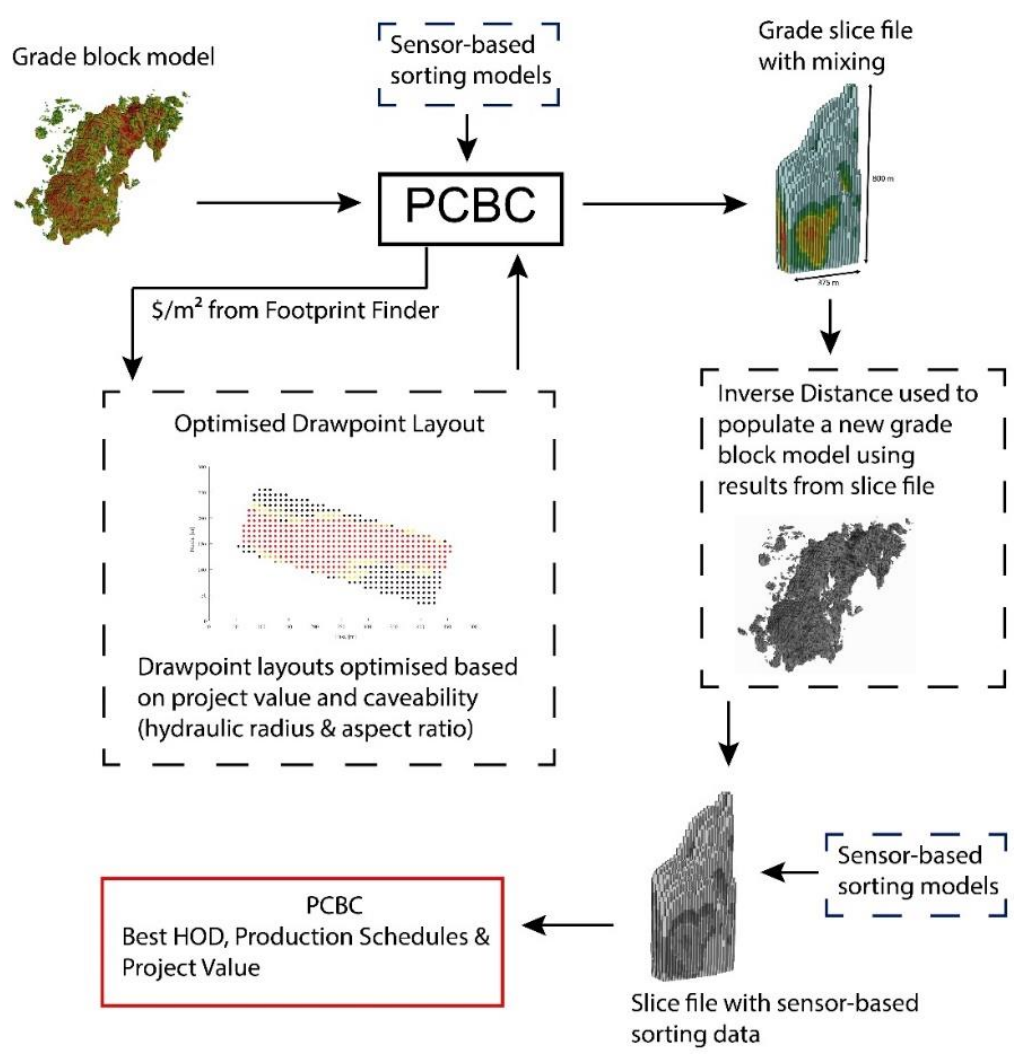

Figure 1 Summary of approach to cave-sorting evaluation

The key steps of the proposed method include:

1. Assessing the applicability of bulk and/or particle grade sensors to material from the deposit.

2. Relating sorting models to material head grade.

3. Populating the block model with sorting parameters for integration with the PCBC production scheduling module. 
4. Nominating the footprint geometry, orientation and elevation using Footprint Finder.

5. Generating a mixed slice file. Updating the grade block model with mixed slice data using inverse distance weighting.

6. Populating the updated grade block model with sorting parameters.

7. Calculating the BHOD for each drawpoint and running production schedules to estimate project value, waste rejection and throughput rates for sorting and milling equipment.

\subsection{Sensor-based sorting assessment}

Bulk and particle sorting systems provide value opportunities for cave mining operations as separate applications or as an integrated bulk and particle sorting system. The potential for sorting is determined though analysis of grade heterogeneity within the orebody at the scale of the intended sorting unit size. For example, cave-scale heterogeneity is relevant to bulk sorting systems, where the sorting unit size (directly related to the practical response time of sensors and diverters) is in the range of 10 to $200 \mathrm{t}$. For particle sorting applications, where particles range from 20 to $100 \mathrm{~mm}$, the heterogeneity within lots of material having a size of approximately $1 \mathrm{t}$ is relevant to sorting performance. In both bulk and particle sorting cases, greater heterogeneity represents more opportunity to add value to a caving project.

The applicability of sensor technologies, which can be exclusive to either bulk or particle sorting applications, needs to be assessed through test methods which are specific to each technology. An example flow sheet where bulk and particle sorting systems are combined is shown in Figure 2. The work was presented in Nadolski et al. (2018) as part of a cave-to-mill study at the New Afton mine, where PGNAA and XRF sensors were found to be applicable for bulk and particle sorting, respectively. Based on the grade measurement from a bulk sensor, a mechanised diverter separates the material into high-grade, intermediate-grade and waste stockpiles. Low-grade material that is transported on the underground-to-surface conveyor is dumped to a waste stockpile and high-grade material is sent directly to the mill. Intermediate-grade material is sent to a crushing, screening and sorting plant where coarse material $(+12.5 \mathrm{~mm})$ is upgraded with a particle sorting system. The fines are either milled or dumped to a waste stockpile depending on the head grade measured by the bulk sensor at the time when it was conveyed from underground. The flow sheet shown in Figure 2 is the basis for the case study presented in this paper.

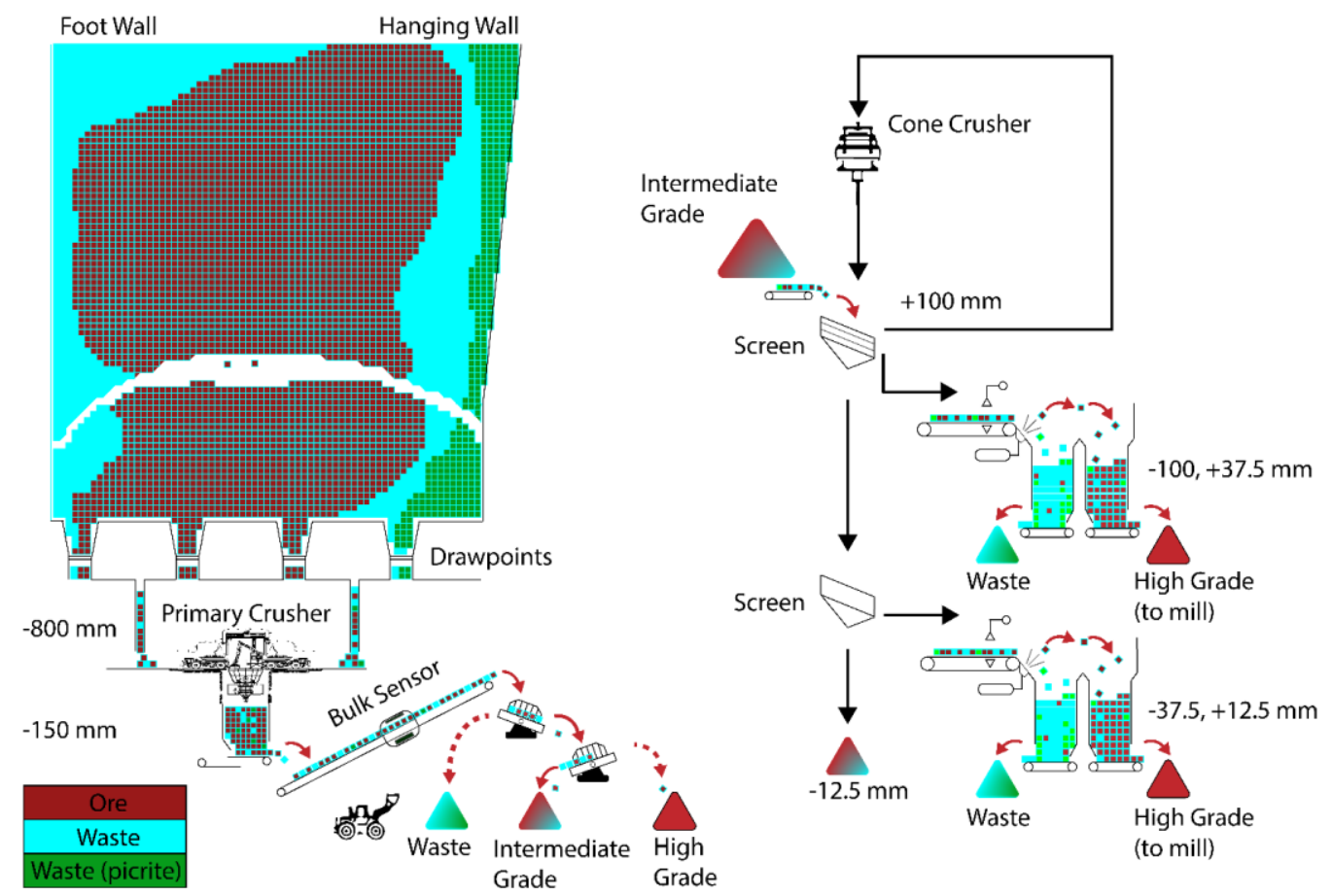

Figure 2 Simplified flow sheet of the mine and sorting systems (Nadolski et al. 2018) 


\subsection{Relating sorting performance to head grade}

Relationships between heterogeneity and grade typically exist on bulk and particle scales, making it possible to effectively link sorting performance to the head grade of each block within a block model. At the New Afton block cave mine, it was found that lower grade caved material was more heterogenous; both on bulk and particle sorting scales (Erdenebat 2017).

To predict the properties of ore above a proposed extraction level layout, PCBC applies cave mixing models to generate a slice file, where rock mass data is arranged according to draw cones, representing the flow geometry of ore above drawpoints. Each draw cone is split into slices that contain grade and other additive information for the caved rock. The size of each slice is related to drawpoint spacing and the height of blocks within the grade block model. Therefore, nominating block size is an important parameter that will affect the quality of sorting predictions. The block size should be nominated with careful consideration to geostatistical implications, which are outside the scope of this paper, and the sorting unit size of the bulk sorting technology being assessed.

In the case of establishing linkages between particle sorting performance and head grade, various drill core or drawpoint materials from existing caves within the deposit should be collected to cover a range of grades and lithology/oxidation types including waste rock. Sensor-based sorting tests for the relevant technology can then provide critical parameters, such as metal recovery and mass pull, to relate to head grade.

During sorter operation, the mass pull of the sorting system can be controlled by modifying the cutoff grade (by way of changing a sensor threshold) for accepting and rejecting particles. The optimum mass pull for a sorting unit is a function of several parameters including metal value and costs for processing and material handling. Table 1 shows an example set of assumptions for the case study where the economic metals are copper and gold.

Table 1 Cost and process assumptions for a caving case study (Nadolski et al. 2018)

\begin{tabular}{lll}
\hline Process & Units & Value \\
\hline Cu price & USD/lb & 2.90 \\
Au price & USD/oz & 1,290 \\
Silver price & USD/oz & 17 \\
Loading (screening plant cost) & USD/t & 0.65 \\
Milling cost & USD/t of mill feed & 9 \\
Waste disposal cost & USD/t & 2.48 \\
Screening, crushing and sorting cost & USD/per tonne of screen feed & 0.80 \\
Percentage passing $12.5 \mathrm{~mm}$ & $\%$ & 34 \\
Grade of unsorted fines $(\sim 20 \mathrm{~mm})$ & $\%$ of head grade & 75 \\
\hline
\end{tabular}

Using the cost parameters shown in Table 1, the economic mass pull and recovery for a range of feed grades was determined and is shown in Figure 3. The following are models that are presented in the figure. Further details on deriving the equations are shown in Nadolski et al. (2018).

$$
\begin{gathered}
\text { Economic Sorter Mass Pull }=40.04 e^{0.64 f_{\text {sorterfeed }}}-40.04 e^{-3.00 f_{\text {sorter feed }}} \\
\text { Economic } R_{\text {Sorter }}=88 e^{0.11 f_{\text {sorter feed }}}-88 e^{-15.09 f_{\text {sorter feed }}}
\end{gathered}
$$

where:

$$
f_{\text {sorterfeed }}=\text { grade of sorter feed. }
$$


The grade of sorter feed, a coarse stream of material, will in most cases be different from the head grade due to metal-bearing minerals reporting preferentially to fine or coarse streams following crushing and screening. An estimate for the proportion of fines, which are not upgradeable by particle sorters, is required to complete the mass balance and evaluate metal recovery. Equation 3 relates the grades of screen feed, oversize and fines, and the proportion of fines.

$$
f_{\text {sorter feed }}(\%)=\frac{f .\left(1-\text { fines upgrade. } P_{\text {fines }}\right)}{\left(1-P_{\text {fines }}\right)}
$$

where:

$$
\begin{aligned}
f & =\text { grade of screen feed (run-of-mine material). } \\
\text { fines upgrade }= & \text { grade of screened out fines as a percentage of head grade. } \\
P_{\text {fines }} & \text { proportion of feed that passes through the sorter screen (typically using an } \\
& \text { aperture size of } 10 \text { to } 30 \mathrm{~mm} \text { ). }
\end{aligned}
$$

Equations 1 to 3 are combined to determine the sorting performance associated with each unit of material reporting from the cave. The net smelter return (NSR) can then be calculated for each processing option available for a unit of material: (i) direct processing, (ii) particle sorting, and (iii) waste. The option with the highest NSR is nominated for diversion to the corresponding stockpile by the bulk sorter.

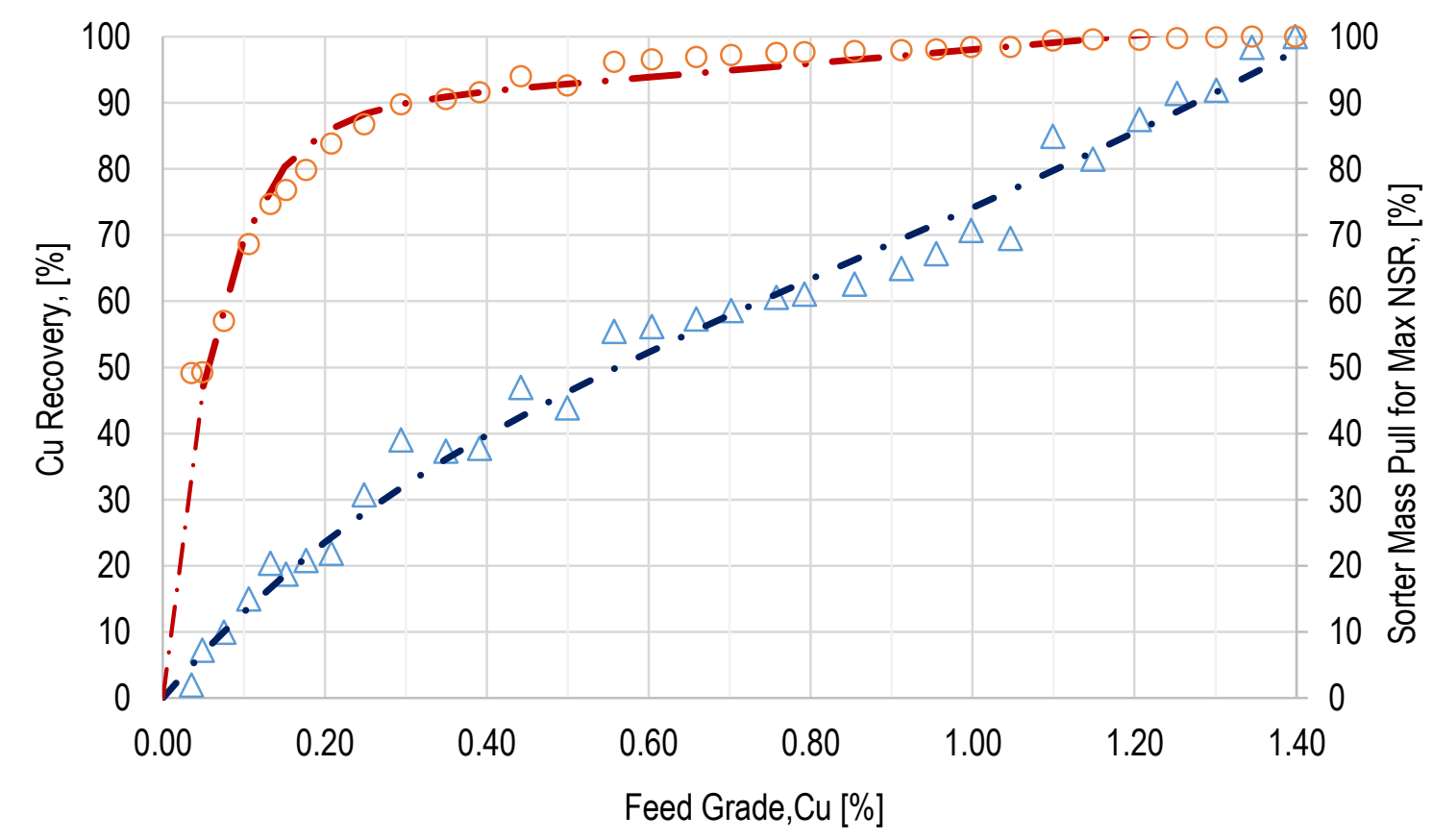

$$
\triangle \text { Mass Pull } \bigcirc \text { Recovery }-\cdots \text { - Mass Pull Model }-\cdot \text { Recovery Model }
$$

Figure 3 Economic mass pull and corresponding copper recovery in relation to material grade (Nadolski et al. 2018)

\subsection{Nominating footprint geometry, orientation and elevation}

Once sorter models are available as a function of head grade, they can be applied to the grade block model to define the block NSR, and the sorter mass pull and recovery for each block. To run a high-level comparison of extraction level sizes and elevations, the Footprint Finder function in the PCBC module provides the value of each unit area $\left(\$ / \mathrm{m}^{2}\right)$ for a range of elevations. The outputs can be exported in spreadsheet form so that a footprint area, horizontal location and elevation that represents a high project net present value can be identified in external packages (e.g. MATLAB or Excel). Practically, the footprint geometry is constrained by 
the caveability of the rock mass and the nominated drawpoint spacing and drift dimensions. An example of costing, caveability and design inputs is shown in Table 2.

Table 2 Example of cave design and costing parameters for a copper-gold case study

\begin{tabular}{lll}
\hline Item & Units & Value \\
\hline Mining cost & USD/t & 11 \\
Development cost per footprint area & USD $/ \mathrm{m}^{2}$ & 5,800 \\
Drawpoint spacing, minor & $\mathrm{m}$ & 15 \\
Drawpoint spacing, major & $\mathrm{m}$ & 20.9 \\
Drift, width $\times$ height & $\mathrm{m}$ & $4.2 \times 4.2$ \\
Vertical caving rate & $\mathrm{m} /$ year & 40 \\
Minimum aspect ratio (length to width) & $(-)$ & 3 \\
Minimum hydraulic radius & $(\mathrm{m})$ & 30 \\
Development rate & Drawpoints per month & 8 \\
Discount rate & $\%$ & 8 \\
\hline
\end{tabular}

Based on sorting data and conceptual cave data, Figure 4 shows the footprint area and elevation that provides maximum project value while adhering to the constraints shown in Table 2. Footprints for various sorting flowsheets can be compared to the nominal footprint that has been solved, assuming sorting systems are not implemented. From the figure, it can be seen that a proportion of the footprint has lesser value (black) and is only developed to adhere to geometric constraints for hydraulic radius and aspect ratio. To reduce the risk of cave stall, a minimum height of draw of $50 \mathrm{~m}$ was assigned to all drawpoints within the footprint. The cost of processing material from marginal drawpoints is reduced by rejecting low-grade material prior to the mill.

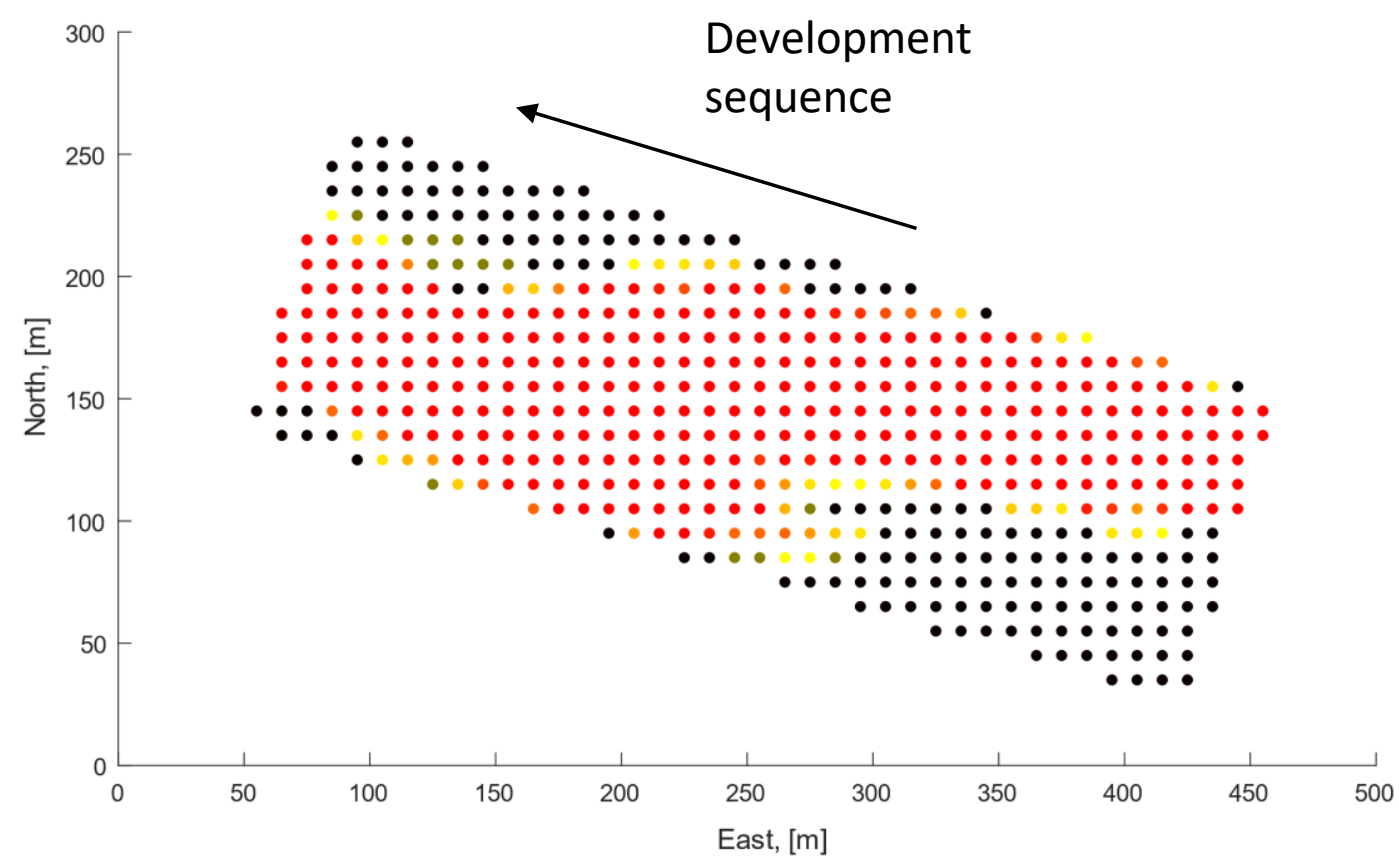

Figure 4 Plan view of a conceptual cave footprint for a proposed extraction level elevation and sorting scenario. Red data points refer to high-value areas of the footprint 


\subsection{Applying models to mixed material in draw cones}

Since PCBC scheduling software, in its current form, does not allow for input of sorter models within the production scheduling routine, sorter models are applied in a three-step approach.

1. A slice file is generated for all drawpoints in the proposed layout. During slice file creation, mixing models are applied based on estimates for the height of the mixing horizon and draw cone diameter, both of which relate to fragmentation size.

2. The grade block model is updated using inverse distance weighting of data from the mixed slice file.

3. Sorter models and NPV calculations are applied to blocks within the updated grade block model, which now includes a more accurate representation of material that will report to drawpoints.

To prepare for production scheduling, a final slice file is generated with no mixing applied.

\subsection{Production scheduling and evaluation}

The BHOD, acting as a limit for drawpoint tonnage, is calculated for each drawpoint based on the final slice data, the draw strategy using the production rate curve (PRC) and draw cone profiles. Figure 5 shows an example of a production schedule for the case study. Typical run-of-mine production would follow the blue 'actual' curve, whereas mill feed production rates following sorting would follow the 'mill feed' curve. Results show that approximately $21 \%$ of low-grade material could be rejected by bulk and particle sorters prior to the mill, while achieving a metal recovery of $97 \%$. Table 3 shows the corresponding mass balance, where it can be seen that the use of bulk sorting significantly reduces the capacity requirements of screening and particle sorting equipment.

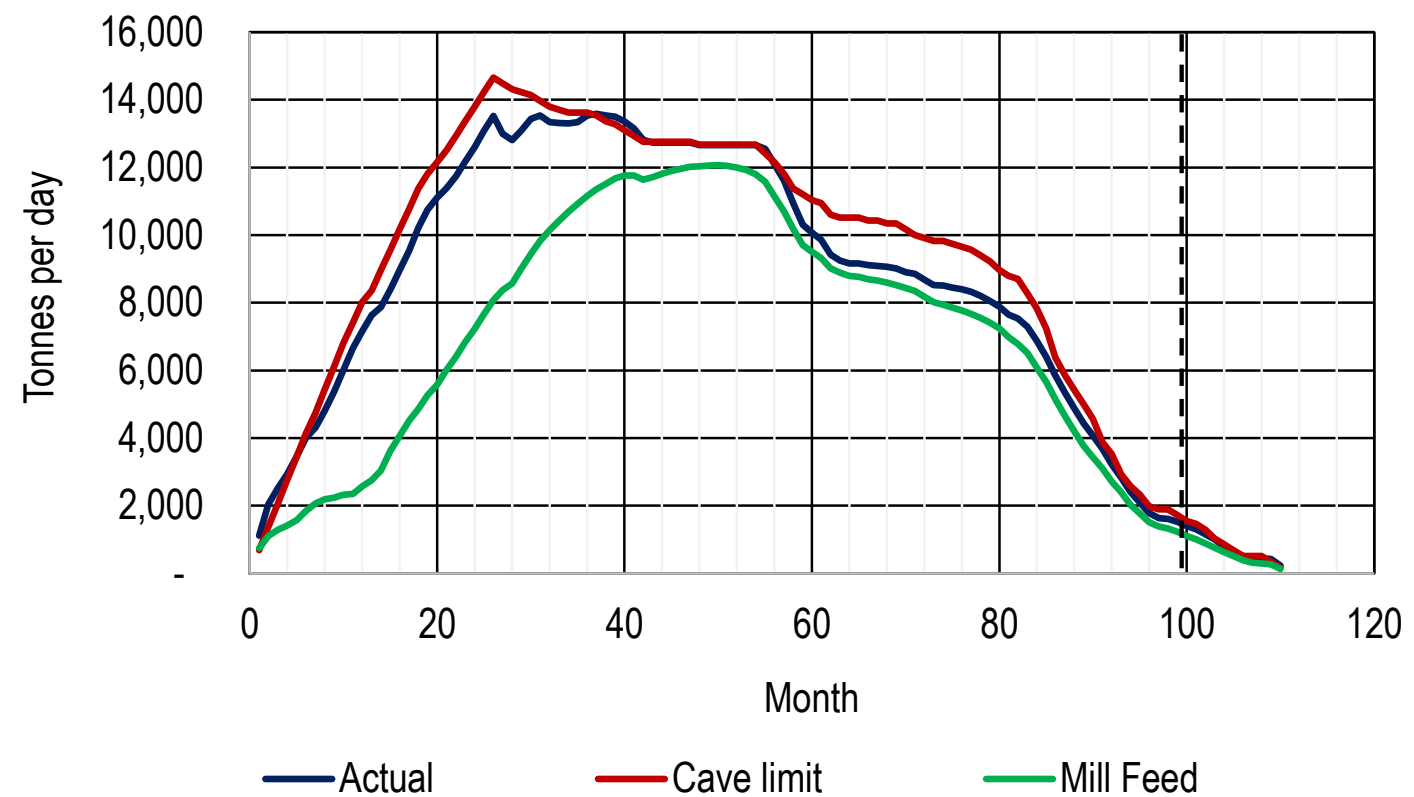

Figure 5 Example production schedule runs for a conceptual cave

The mass balance shown in Table 3 provides valuable input for sizing of screens, sorters and mill equipment. 
Table 3 Mass balance for a conceptual cave

\begin{tabular}{lll}
\hline Stream & Mass proportion (\%) & Metal proportion (\%) \\
\hline Bulk sorter feed (run-of-mine) & 100 & 100 \\
Bulk sorter, high-grade stream (to mill) & 66.7 & 92.2 \\
Particle sorter concentrate & 4.1 & 4.6 \\
Particle sorting plant, fines (to mill) & 8.4 & 0.8 \\
Particle sorter, waste & 12.1 & 2.1 \\
Bulk sorter, waste & 8.7 & 0.3 \\
Total mill feed & 79.2 & 97.6 \\
\hline
\end{tabular}

\section{Discussion and conclusion}

The nature of cave operations makes them ideal for the incorporation of sensor-based systems to reject rock and allow the operation to become more efficient. The presented method provides a means to design and evaluate a block or panel cave for the case where sensor-based sorting systems are included in the flow sheet. The resulting mass balance can be used for stockpile estimation and equipment sizing to estimate the capital cost savings associated with lower mill throughput requirements. Using the method, changes in footprint size, project value and life-of-mine metal production can be compared to alternative scenarios where sorting systems are not in place.

The implementation of bulk sorting systems on underground-to-surface conveyors or integrated with production shafts prompts reconsideration of underground production scheduling. For example, campaigning of low-grade and high-grade ore from drawpoints will reduce blending within orepasses and downstream material-handling systems, and improve sorting performance.

\section{Acknowledgement}

The authors thank personnel at New Afton and New Gold for supporting the cave-to-mill project and for providing access to samples and data from the New Afton block cave operation. Marty Henning of New Gold assisted with sample selection and provided input throughout the course of the project. Truong Bui and Christina Ludwicki of Dassault Systèmes provided support with the application of PCBC. The authors also thank the Natural Sciences and Engineering Research Council of Canada (NSERC) for the financial support provided to this research through a Collaborative Research Development Grant (Grant No. 11R74149; Mineto-Mill Integration for Block Cave Mines).

\section{References}

Coghill, P, Cutmore, N, Lehmann-Horn, J, Lovric, B, McEwen, A, Milinkovic, D, Miljak, D, Roberts, G \& Yong, R 2018, 'Demonstration of a magnetic resonance analyser for bulk copper sorting', in T Pretz, H Wotruba \& A Feil (eds), Proceedings of the Eighth Conference on Sensor-Based Sorting \& Control, RWTH Aachen University, Aachen, pp. 152-160.

Dassault Systèmes 2018, GEOVIA PCBC, version 6.8.1, computer software, Dassault Systèmes, Paris, https://www.3ds.com/productsservices/geovia/products/pcbc/

Diering, T, Richter, O \& Villa, D 2010, 'Block cave production scheduling using PCBC', Proceedings of the SME Annual Meeting, Society for Mining, Metallurgy \& Exploration, Englewood.

Erdenebat, E 2017, Study of New Afton Ore Heterogeneity and its Amenability to Sensor Based Ore Sorting, MASc thesis, The University of British Columbia, Vancouver.

Klein, B \& Bamber, AS 2018, chapter on mineral sorting, in R Dunne, C Young \& SK Kawatra (eds), SME Mineral Processing and Extractive Metallurgy Handbook, Society for Mining, Metallurgy \& Exploration, Englewood, in press.

Kobzev, A 2014, 'History of sensor-based sorting in CIS', in T Pretz, H Wotruba \& A Feil (eds), Proceedings of the Sixth Conference on Sensor-based Sorting, RWTH Aachen University, Aachen, pp. 39-48.

Nadolski, S, Samuels, M, Klein, B \& Hart, CJR 2018, 'Evaluation of bulk and particle sensor-based sorting systems for the New Afton block caving operation', Minerals Engineering, vol. 121, pp. 169-179.

Teck Resources 2018, Building a Smarter Shovel, Teck Resources, Vancouver, viewed 5 May 2018, https://www.teck.com/news/ stories/2018/building-a-smarter-shovel 